\title{
Expression of basic fibroblast growth factor is associated with poor outcome in non-Hodgkin's lymphoma
}

\author{
I Pazgal', Y Zimra', C Tzabar², E Okon ${ }^{2,3}$, E Rabizadeh', M Shaklai ${ }^{1,3}$ and O Bairey*,1,3 \\ 'Institute of Hematology and Felsenstein Medical Research Center, Rabin Medical Center, Beilinson Campus, Petah Tiqva, 49 I 00, Israel; ${ }^{2}$ Institute of Pathology, \\ Rabin Medical Center, Beilinson Campus, Petah Tiqva, 49100, Israel; ${ }^{3}$ Sackler Faculty of Medicine, Tel Aviv University, Tel Aviv, Israel
}

It is now clear that angiogenesis and angiogenesis factors are important in the pathogenesis of haematological malignancies. High pretreatment levels of serum basic fibroblast growth factor have been shown to be associated with poor prognosis in patients with non-Hodgkin's lymphoma. The aim of this study was to evaluate whether non-Hodgkin's lymphoma cells express basic fibroblast growth factor and/or its receptor (fibroblast growth factor receptor-I) and whether basic fibroblast growth factor expression correlates with basic fibroblast growth factor serum levels, intratumoral microvessel density, and patient outcome. We measured basic fibroblast growth factor by enzyme-linked immunosorbent assay in sera taken from 58 patients with non-Hodgkin's lymphoma before treatment and in 19 of them also after treatment. Pathological specimens at diagnosis were evaluated by immunohistochemistry staining using polyoclonal antibody against factor-VIII-related antigen, basic fibroblast growth factor and fibroblast growth factor receptor-I to determine the expression of the microvessel count and basic fibroblast growth factor and fibroblast growth factor receptor- I. The lymphoma specimens demonstrated positive staining for basic fibroblast growth factor (in 23\%) and fibroblast growth factor receptor-I (in 58.5\%). The patients who expressed basic fibroblast growth factor had a significantly worse progression-free and overall survival than those who did not $(P=0.003$ and $P=0.03$ respectively), while patients expressing fibroblast growth factor receptor-I were less likely to achieve complete remission than those lacking the receptor ( $33 \%$ vs $65 \%, P=0.047$ ). There was no correlation of basic fibroblast growth factor staining with either serum basic fibroblast growth factor levels or microvessel count. Basic fibroblast growth factor serum levels did not change significantly after treatment These results suggest that non-Hodgkin's lymphoma specimens express basic fibroblast growth factor and its receptor (fibroblast growth factor receptor-1) and this expression is associated with poor patient outcome.

British Journal of Cancer (2002) 86, 1770 - 1775. doi: I 0.1038/sj.bjc.6600330 www.bjcancer.com

(c) 2002 Cancer Research UK

Keywords: basic fibroblast growth factor; basic fibroblast growth factor receptor; immunohistochemistry; non-Hodgkin's lymphoma; microvessel count

Angiogenesis is necessary for the growth of solid tumours and the dissemination of malignant cells (Folkman, 1990). Recent evidence also points to a role of angiogenesis and angiogenesisrelated molecules in haematological malignancies (Mangi and Newland, 2000). Tumours promote angiogenesis by secreting growth factors that stimulate endothelial cell migration and capillary proliferation. Angiogenic activity is regulated by the balance between positive and negative angiogenic regulators (Iruela-Arispe and Dvorak, 1997). Basic fibroblast growth factor (bFGF), an 18to $24-\mathrm{kD}$ polypeptide, serves as a key positive angiogenic regulator in vivo (Bikfalvi et al, 1997). It also stimulates endothelial cell proliferation in vitro and regulates the expression of several molecules thought to mediate critical steps in the angiogenesis process (Basilico and Moscatelli, 1992). bFGF is mainly produced by cells of mesenchymal origin. $\mathrm{T}$ cells, macrophages, and granulocytes also have the capacity to produce bFGF (Salven et al, 1999). It is normally bound to heparin and heparan sulphate

* Correspondence: $\bigcirc$ Bairey; Institute of Hematology, Rabin Medical Center, Beilinson Campus, Petah Tiqva 49I00, Israel;

E-mail: obairey@post.tau.ac.il

Received 3 January 2002; revised 26 March 2002; accepted 27 March 2002 proteoglycans in the extracellular matrix, particularly in basement membranes, around vessels and stromal cells. It binds to a family of four distinct, high-affinity tyrosine kinase receptors, designated FGFR-1 -4 .

Until recently, measurement of intratumoral microvessel density by immunocytochemistry appeared to be the most reliable method of assessing angiogenic activity (Toi et al, 1996). An alternative method for evaluating angiogenic activity is the determination of the levels of each angiogenic factor in tumour tissues and serum (Poon et al, 2001). There are very few studies of angiogenesis in non-Hodgkin's lymphoma (NHL). Ribatti and his group (Ribatti et al, 1996) assessed the microvessel count with factor VIII staining in 88 patients with NHL and 15 with benign lymphadenopathies. Their count covered the whole specimens. They found that angiogenesis is more intense in the stroma of B-NHL than of benign lymphadenopathies, and increases in more aggressive tumours. In lymphadenopathies and follicular subtypes of NHL, very few vessels were observed within follicles, and numerous in uninvolved tissue between the follicles. By contrast, all diffuse subtypes of NHL showed vessels throughout the tumour tissue. Salven et al (1999) measured serum bFGF in 160 newly diagnosed patients with NHL and found that a high pretreatment serum bFGF was associated with poor overall survival. 
In the present study, we measured serum bFGF concentration before and after treatment in patients with NHL. We also conducted a biopsy study to determine the expression of bFGF and its receptor FGFR-1 and the microvessel count (MVC) in biopsies taken at diagnosis. Finally, we evaluated the prognostic significance of bFGF and FGFR-1 expression in NHL patients.

\section{PATIENTS AND METHODS}

\section{Patients}

Serum bFGF concentration was measured in 58 adult patients with NHL diagnosed and treated in the Division of Hematology, Rabin Medical Center, Beilinson Campus from 1997 to 1999. Approval was obtained from the local ethics committee. Serum was taken at the time of diagnosis, before lymphoma treatment was administered. In 19 patients, serum bFGF concentration was also measured after 2-3 cycles of chemotherapy.

The clinical and pathological characteristics of the patients are shown in Table 1.There were 26 male (45\%) and 32 females $(55 \%)$ of mean age 64.5 years (range $25-90)$.The histological types according to the WHO classification (Harris et al, 1999) were as follows: small lymphocytic lymphoma, six patients (10\%); follicular lymphoma, 11 patients (19\%); diffuse large B-cell lymphoma (DLBCL), 36 patients (62\%); extranodal marginal zone B-cell lymphoma, one patient (2\%); mantle cell lymphoma, three patients (5\%), and precursor T-lymphoblastic lymphoma, 1 patient $(2 \%)$. Clinical staging at diagnosis was done according to the Ann Arbor classification system: 13 (22\%) patients had stage I, five (9\%) stage II, eight (14\%) stage III, and 32 (55\%) stage IV. Sixteen specimens $(27 \%)$ were of extranodal origin and the rest were of nodal origin. Seventeen patients $(29 \%)$ had bulky disease at presentation (largest

Table I Characteristics of $58 \mathrm{NHL}$ patients

\begin{tabular}{lc}
\hline Mean age (years) & 64.5 \\
Range (years) & $25-90$ \\
Sex & \\
Female & $32(55 \%)$ \\
Male & $26(45 \%)$ \\
Pathology-hostological type Small lymphocytic lymphoma & $6(10 \%)$ \\
Follicular lymphoma & $11(19 \%)$ \\
Diffuse large B-cell lymphoma & $36(62 \%)$ \\
Extranodal marginal zone B-cell lymphoma & $1(2 \%)$ \\
Mantle cell lymphoma & $3(5 \%)$ \\
Precursor T-lymphoblastic lymphoma & $1(2 \%)$ \\
Stage & \\
I & $13(22 \%)$ \\
II & $5(9 \%)$ \\
III & $8(14 \%)$ \\
Extranodal & $32(55 \%)$ \\
Bulky disease (> I0 cm) & $16(27 \%)$ \\
Elevated serum LDH & $17(29 \%)$ \\
International Prognostic Index: & $20(34.5 \%)$ \\
0 & \\
I & $7(12.5 \%)$ \\
2 & $8(14 \%)$ \\
3 & $16(28.5 \%)$ \\
4 & $14(25 \%)$ \\
Median follow-up time (months) & $6(11 \%)$ \\
Range & $5(11 \%)$ \\
Treatment & 29.5 \\
None & $1-49$ \\
Radiotherapy & \\
Radiotherapy and chemotherapy & $11(19 \%)$ \\
Stem cell transplantation & $4(7 \%)$ \\
\hline & $4(7 \%)$ \\
\hline & $43(74 \%)$ \\
Chemotherapy & $3 \%)$ \\
\hline
\end{tabular}

diameter $\geqslant 10 \mathrm{~cm})$ and $20(34.5 \%)$ had elevated serum lactate dehydrogenase (LDH) levels at diagnosis. The International Prognostic Index (IPI) (The International Non-Hodgkin's Prognostic Factor Project, 1993) was determined in 56 patients. The score was 0 in seven patients $(12.5 \%)$; one in eight patients $(14 \%)$; two in 16 patients $(28.5 \%)$; three in 14 patients $(25 \%)$; four in six patients $(11 \%)$, and five in five patients $(9 \%)$.

Eleven patients did not receive any treatment. Four patients received only radiotherapy and another four received radiation combined with chemotherapy. Low-grade lymphomas were usually treated with chlorambucil alone or combined with prednisone if symptomatic. Intermediate-grade lymphomas were usually treated with CHOP (cyclophosphamide, doxorubicin, vincristine and prednisone) or another anthracycline-containing combination chemotherapy regimen. Three patients underwent stem cell transplantation, two autologous and one allogeneic.

Median follow-up time was 29.5 months (range 1-49). During follow-up, 13 patients died.

\section{Methods}

Serum bFGF immunoassay Peripheral venous blood samples were collected in empty tubes, centrifuged at $2000 \mathrm{~g}$ for $10 \mathrm{~min}$, and stored at $-70^{\circ} \mathrm{C}$. The level of bFGF in serum was determined with a commercial quantitative sandwich enzyme immunoassay technique (Quantikine R; R\&D Systems, Minneapolis, MN, USA). The system uses a solid-phase monoclonal antibody and an enzyme-linked polyclonal antibody raised against recombinant human bFGF. All analyses and calibrations were performed in duplicate.

Immunohistochemistry for factor-VIII-related antigen, bFGF and FGFR-1 All specimens were archival material of biopsies taken at the time of lymphoma diagnosis that had been fixed in neutral-buffered formalin and embedded in paraffin by routine methods. Paraffin-embedded tumour specimens were cut into 4$\mu \mathrm{m}$ thick sections and mounted on adhesive-coated glass slides. Deparaffinisation and hydration were performed through xylene and graded alcohol series. The slides were washed in distilled water and heated twice in citrate buffer $(\mathrm{pH} \mathrm{6.0)}$ in a pressure cooker that was placed in a microwave oven for 15 and 5 min at $700 \mathrm{~W}$ to retrieve the antigenicity. Endogenous peroxidase activity was then blocked by incubation for $15 \mathrm{~min}$ at room temperature with $\mathrm{H}_{2} \mathrm{O}_{2}$ (3\%) in methanol followed by washing with phosphatebuffered saline (PBS). The slides were then incubated with one of the following primary antibodies: (1) rabbit anti-human, antifactor-VIII-related antigen (F8RA), (Dako, CA, USA) at a dilution of $1: 1000$ for $45 \mathrm{~min}$ at room temperature; (2) rabbit anti-human, anti-bFGF polyclonal antibody (Biotechnology, Inc; Santa Cruz, CA, USA) at a dilution of $1: 500$ for $45 \mathrm{~min}$ at room temperature; (3) rabbit anti-human, anti-FGFR-1 polyclonal antibody (Biotechnology, Inc.) at a dilution of $1: 800$ for $45 \mathrm{~min}$ at room temperature. The primary antibodies against F8RA and FGFR-1 were detected by the Strept A-B immunoperoxidase staining universal kit ( $\left.\mathrm{LSAB}^{+} \mathrm{Kit}, \mathrm{Dako}\right)$ according to the manufacturer's instructions. The primary antibody against bFGF was detected by the DAKO EnVision ${ }^{\mathrm{TM}}+$ System. This system is based on HRPlabelled polymer that does not contain avidin or biotin and therefore eliminates nonspecific staining from endogenous avidin-biotin activity, which was very high with the Dako $\mathrm{LSAB}^{+}$kit. Diaminobenzidine was used as chromogen, and incubation was conducted for $5 \mathrm{~min}$ at room temperature. Sections were counterstained in haematoxylin. A negative control omitting the primary antibody was used in each experiment. For positive control of bFGF, we stained specimens of normal breast, in which bFGF is known to be localised in the myoepithelial cells (Yiangou et al, 1997). For positive control of FGFR-1, we stained specimens of breast carcinoma which is known to display FGFR-1 expression in neoplastic 
cells (Blanckaert et al, 1998). The lymphoid cells in reactive lymph node showed positive staining for bFGF and negative staining for FGFR-1, which did stain the blood vessels.

Immunohistological scoring The areas of highest protein expression evident at low-power scanning were taken for analysis. Staining was considered negative only after careful examination of the entire tissue section under high power $(\times 1000)$. Quantitation of the number of positive tumour cells was performed simultaneously by two investigators (I Pazgal, O Bairey) blinded to the clinical outcome. A double-headed light microscope was used to score at least 500 cells in high power fields. In cases in which the investigators disagreed, the immunohistochemical staining was repeated, and a third reviewer (E Okon) scored the slides in a blinded fashion. Specimens that contained $>10 \%$ immunostained tumour cells were defined as immunopositive; those with $\leqslant 10 \%$ were defined as immunonegative.

Microvessel count Microvessel count (MVC) was assessed with a light microscope. The whole tumour section was scanned at a low magnification $(\times 100)$, and the area of the most intense vascularisation (hot spot) was determined. Any brown-staining endothelial cell or endothelial-cell cluster that was clearly separated from adjacent microvessels, tumour cells and connective tissue elements was considered a single countable microvessel. The presence of a vessel lumen was not necessary for a structure to be defined as a microvessel. Vessels within sclerotic areas were not included. Individual microvessel counts were made on a $\times 200$ field $\left(0.785 \mathrm{~mm}^{2}\right.$ per field). Quantitation of the number of microvessels was performed simultaneously and independently by two investigators (O Bairey, I Pazgal) blinded to the clinical outcome. The mean number of microvessels per sample was calculated and was taken as the MVC for each case.

Statistical analysis Statistical analysis was performed using an SPSS statistical software program (SPSS Inc. Chicago, IL, USA). Either $t$-test or $\chi^{2}$ analysis (Fisher exact test) was used for statistical comparison of the clinical and laboratory characteristics and bFGF serum levels or bFGF and its receptor expression and MVC. Analysis of Variance (ANOVA) was used to compare bFGF levels between different clinical groups. Progression-free survival (PFS) was calculated from date of diagnosis to date of disease progression, relapse or death. Survival and PFS were computed according to the product-limit method of Kaplan-Meier from the date of diagnosis. The log rank test was used to compare survival rates between different subgroups of patients. The relative influence of different variables on survival was studied by multivariate survival analysis using stepwise Cox regression.

\section{RESULTS}

\section{Serum bFGF in patients at diagnosis and after treatment}

Mean serum bFGF concentration in 11 healthy volunteers was $2.5 \pm 3.8 \mathrm{pg} \mathrm{ml}^{-1}$ (range $0-10.5$ ). Serum bFGF concentrations in 58 patients with NHL ranged from undetectable to $28.0 \mathrm{pg} \mathrm{ml}^{-1}$ (mean $5.3 \pm 5.6 \mathrm{pg} \mathrm{ml}^{-1}$ ). There were no significant differences in serum $\mathrm{bFGF}$ concentration by NHL grade, histologic type, stage of disease, IPI index, or treatment protocol. There was also no association between serum bFGF level and patient age, sex and LDH levels. Patients with bulky NHL had significantly higher levels of bFGF $\left(>10 \mathrm{pg} \mathrm{ml}^{-1}\right)$ than patients with non-bulky disease ( $29.4 \%$ and $7.7 \%$ respectively, $P=0.046$ ); no correlation with either overall survival or PFS was found.

In 19 patients, serum bFGF was also assayed after $2-3$ cycles of chemotherapy. Mean bFGF level at that time was $9.6 \mathrm{pg} \mathrm{ml}^{-1}$ (range $0-21.8$ ). There was no correlation between serum bFGF level at diagnosis and after treatment, nor was there a significant change in bFGF levels or a specific trend in patients responding or not responding to treatment.

\section{Microvessel count (MVC)}

Mean MVC, determined in 40 patients was $77.3 \pm 35.7$ (range 20197). Follicular lymphoma specimens demonstrated a distinct pattern of microvessel distribution, with very few microvessels in the area of the follicles but numerous ones in the areas between the follicles (Figure 1). Since the vessels were counted in the areas of most intense vascularisation, (hot spots), in the follicular lymphomas specimens, these areas were always in the interfollicular areas. No correlation was found between mean MVC and grade, stage histology or survival of the patients.

\section{bFGF expression in lymphoma specimens (Figure 3A)}

Staining of lymphoma specimens for bFGF was performed in 39 patients. In nine patients the lymphomas expressed bFGF $(23.1 \%)$. There was heterogeneity of bFGF expression with a mean staining of $51 \%$ of lymphoma cells (range 15-100\%). In most specimens endothelial cells, polymorphonuclear cells, and macrophages stained positive and served as an internal positive control. Positive immunostaining for bFGF was usually present in the cytoplasm of tumour cells, but some cells showed nuclear staining. Lymphoma cell staining correlated strongly with PFS $(P=0.003$, Table 2, Figure $2 \mathrm{~A})$ and overall survival $(P=0.03$, Table 2 , Figure
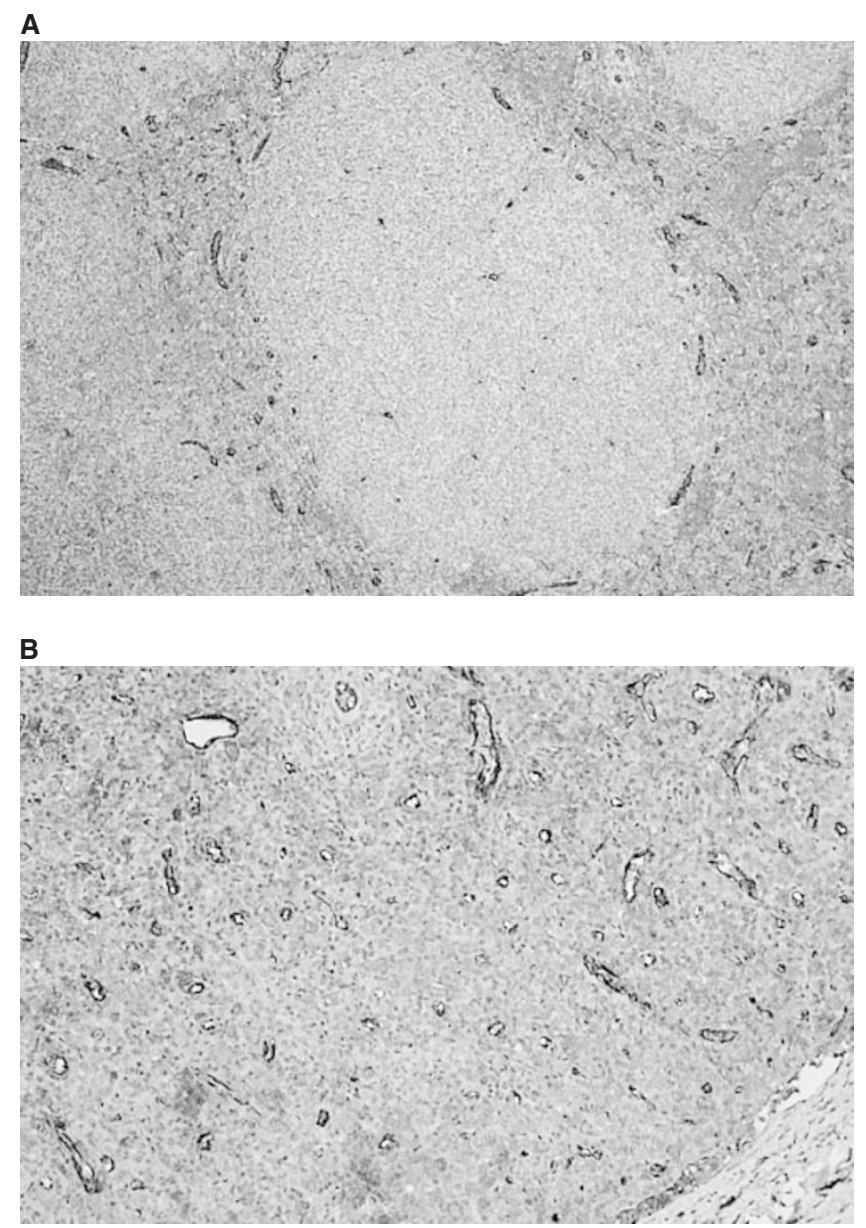

Figure I Microvessels in NHL. Representative field of follicular $\mathrm{NHL}(\mathbf{A})$ and diffuse NHL (B) stained with anti-factor-VIII-related antigen. Note the absence of microvessels in the follicular area. 
A

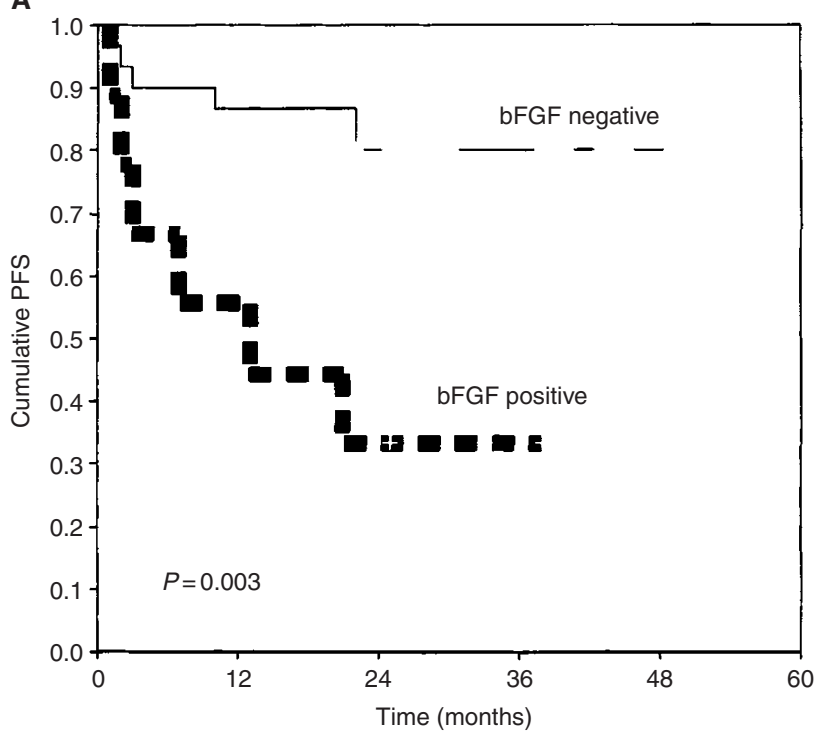

B

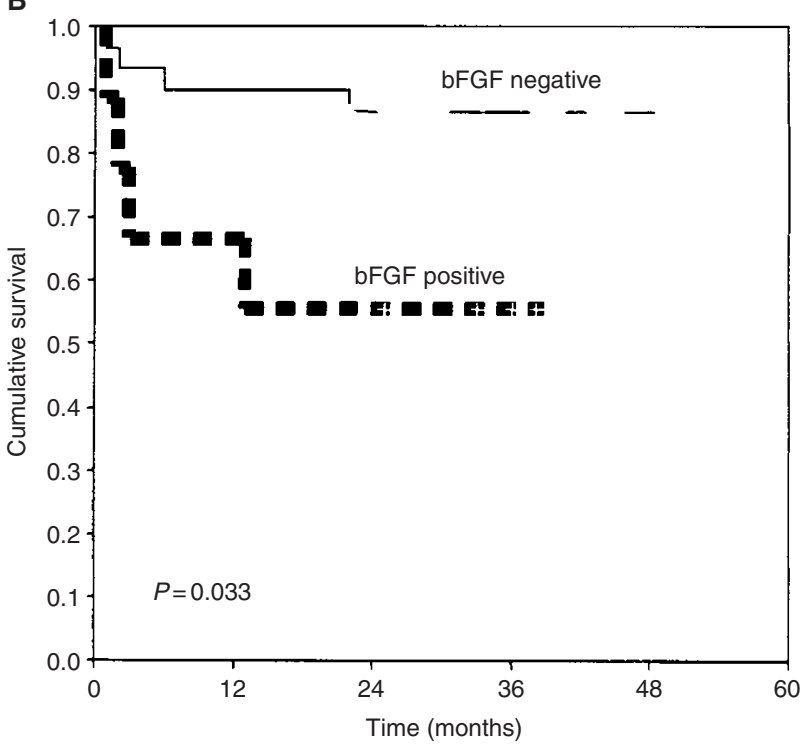

Figure 2 Kaplan-Meier progression-free survival $(\mathbf{A})$ and overall survi$\mathrm{val}$ (B) curves according to bFGF expression for 39 patients with NHL. bFGF expression was positive in lymphomas from nine patients (23\%).

2B), with the patients showing positive staining for bFGF having worse PFS and overall survival. In the nine patients in whom the lymphoma cells stained positive, mean survival was $23.8 \pm 5.8$ months (range 1-38; median survival was not reached)) and mean PFS was $17.9 \pm 5.1$ months (range $1-38$, median 13 months). Four of them died during the study period, and only $33 \%$ had no disease progression. By contrast, of the 30 patients whose specimens stained negative for bFGF, mean survival was $43.5 \pm 2.6$ months (range $1-49$, median survival was not reached) and mean PFS $41.2 \pm 2.9$ months (range $1-49$, median PFS was not reached). Only four patients from this group died during the study period, and $80 \%$ had no disease progression. When survival analysis were carried out in the 25 patients with diffuse large B-cell lymphoma (DLBCL), the patients in whom the lymphoma specimens stained positive for bFGF had significantly worse overall $(P=0.013)$ and PFS ( $P=0.002$, Table 2$)$. There was also a correlation between bFGF staining and bulky disease. Five of the nine patients with lympho-
A

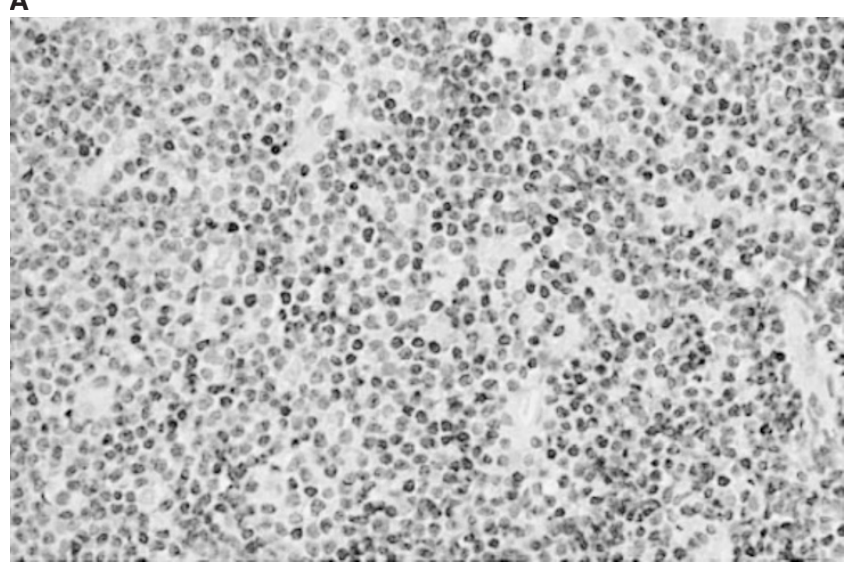

B

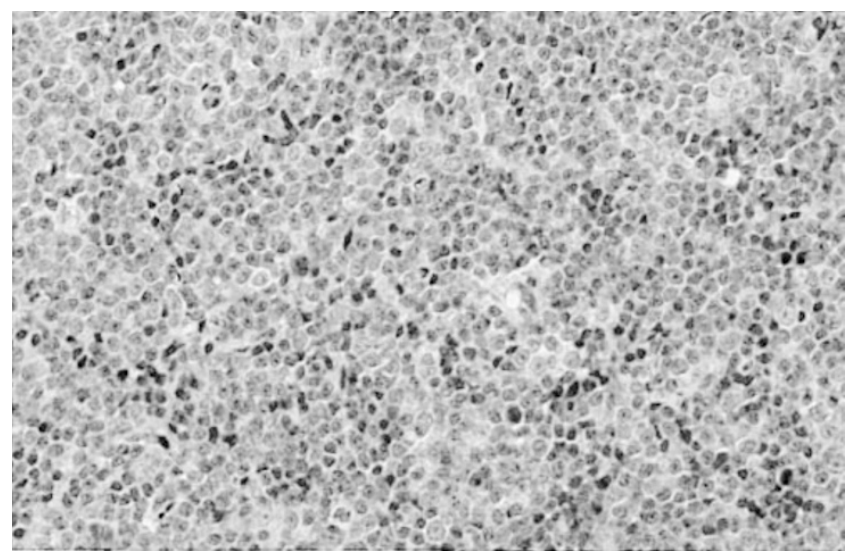

Figure 3 Staining of small lymphocytic lymphoma cells for bFGF $(\mathbf{A})$, FGFR-I (B)

ma which was positive for bFGF staining (55.6\%) had bulky disease compared to $17.9 \%$ of the patients with lymphoma with negative staining $(P=0.04)$. No correlation was found between bFGF staining and serum bFGF concentration, MVC, histology, stage, grade, LDH level, IPI index, or response to treatment.

\section{bFGF receptor expression in lymphoma specimens (Figure 3B)}

Staining of lymphoma specimens for bFGF receptor (FGFR-1) was performed in 41 patients. Results were positive in $24(58.5 \%)$. In most of the positive specimens the staining was cytoplasmatic, but in some, additional nuclear staining or only nuclear staining was evident. Endothelial cells stained positive as did plasma cells, and they served as an internal positive control. A correlation was found between a negative expression of FGFR-1 and the achievement of complete remission $(P=0.047)$. Eleven of the 17 patients with lymphomas with negative staining for FGFR-1 (64.7\%) achieved complete remission compared to only eight of the 24 patients with lymphomas with positive staining (33.3\%). There was also a borderline correlation between FGFR-1 expression and bulky disease $(P=0.07)$, with $39 \%$ of the patients with lymphomas that expressed FGFR-1 having bulky disease compared to $12.5 \%$ of patients with lymphomas who did not. A borderline correlation was noted between the expression of bFGF and its receptor $(P=0.067): 87.5 \%$ of the patients who expressed bFGF in their lymphomas, also expressed FGFR-1, compared to only $50 \%$ of the patients who's lymphomas did not express bFGF. No correlation was found between FGFR-1 staining and serum bFGF 
Table 2 Survival analysis for I. All WHO groups. II. DLBCL group

\begin{tabular}{|c|c|c|c|c|c|c|}
\hline Expression & $\begin{array}{l}\text { Mean PFS } \\
\text { (months) }\end{array}$ & $\begin{array}{c}\text { Median PFS } \\
\text { (months) }\end{array}$ & $P$ value & $\begin{array}{c}\text { Mean overall survival } \\
\text { (months) }\end{array}$ & $\begin{array}{l}\text { Median overall survival } \\
\text { (months) }\end{array}$ & $P$ value \\
\hline \multicolumn{7}{|l|}{ i. All WHO groups } \\
\hline bFGF positive & 17.9 & 13 & & 23.8 & Not reached & \\
\hline bFGF negative & 41.2 & Not reached & 0.003 & 43.5 & Not reached & 0.03 \\
\hline FGFR-I positive & 33.7 & Not reached & Not & & & \\
\hline FGFR-I negative & 39 & Not reached & significant & & & \\
\hline Normal LDH level & 40.1 & Not reached & & 46.0 & Not reached & \\
\hline Increased LDH level & 24.4 & 22.0 & 0.012 & 28.9 & Not reached & 0.0025 \\
\hline $\mid \mathrm{PI}$ index $0-2$ & 40.0 & Not reached & & 47.0 & Not reached & \\
\hline $\mid \mathrm{PI}$ index $3-5$ & 26.2 & Not reached & 0.045 & 28.8 & Not reached & 0.0019 \\
\hline Serum bFGF $\leqslant 3.5$ & 35.9 & Not reached & Not & 39.6 & Not reached & Not \\
\hline Serum bFGF $>3.5$ & 33.8 & Not reached & significant & 38.7 & Not reached & significant \\
\hline \multicolumn{7}{|l|}{ II. DLBCL group } \\
\hline bFGF positive & 15.4 & 13 & & 19.4 & 13 & \\
\hline bFGF negative & 39.3 & Not reached & 0.002 & 39.5 & Not reached & 0.013 \\
\hline FGFR-I positive & 25.5 & 21 & & 27.7 & Not reached & \\
\hline FGFR-I negative & 40.4 & Not reached & 0.035 & 40.42 & Not reached & 0.075 \\
\hline Stages I and II & 35.2 & Not reached & & 35.96 & Not reached & Not \\
\hline Stages III and IV & 23.9 & 14 & 0.02 & 30.05 & Not reached & significant \\
\hline
\end{tabular}

concentration, MVC, histology, stage, grade, LDH level, IPI index or overall survival. When survival analysis was carried out for the 24 patients with DLBCL group alone, there was a significant worse PFS for the patients with positive staining $(P=0.035$, Table $2)$ and borderline worse overall survival $(P=0.075$, Table 2$)$.

\section{Prognostic studies}

The prognosis of patients with NHL is best determined by the IPI index and this was confirmed by the present study $(P=0.002)$. Multivariate analysis by Stepwise Cox regression was used to determine if bFGF expression adds to the predictive value of the IPI for survival. IPI alone still had the strongest predictive value.

\section{DISCUSSION}

The results presented show that bFGF and its receptor FGFR-1 are expressed in NHL. Furthermore, the expression of bFGF and its receptor in lymphoma cells has a prognostic significance: bFGF expression is correlated with worse survival and PFS, and FGFR1 expression is correlated with decreased rate of achievement of complete remission and in the subgroup with DLBCL with worse survival and PFS. Thus, bFGF and its receptor might be involved in the survival and resistance to therapy of NHL cells.

Several lines of evidence have suggested a role of fibroblast growth factors (FGFs) and their receptors (FGFRs) in human cancer (Birnbaum et al, 1991). Basilico and Moscatelli (1992) found that amplification or ectopic expression of FGFs induces cellular transformation. Several carcinomas have shown increased bFGF production by the cancer epithelial cell themselves observed by immunohistochemistry. These include pancreatic (Ohta et al, 1995; Yamazaki et al, 1997) breast (Yiangou et al, 1997; Blanckaert et al, 1998), non-small cell lung (Volm et al, 1997) and head and neck squamous carcinomas (Dellacono et al, 1997). FGFR-1 and FGFR-2 are overexpressed in several human cancers (Birnbaum et al, 1991; Ohta et al, 1995; Yamazaki et al, 1997; Blanckaert et $a l, 1998)$, and some investigators noted a prognostic significance of bFGF expression or bFGF receptors only. In pancreatic carcinomas, expression of bFGF was strongly associated with the tumour cell proliferation (Yamazaki et al, 1997) and with poor prognosis. Ohta et al (1995) reported that increased FGFR-1 expression in pancreatic carcinomas was correlated with decreased survival. In non-small cell lung carcinomas, all tumour specimens expressed some level of bFGF and FGFR-1 (Volm et al, 1997). Patients with high FGFR-1 expression had significantly shorter survival than patients with weak or moderate expression, but no correlation was found between bFGF expression and patient survival. In patients with breast carcinomas, higher levels of bFGF levels were associated with improved overall and disease-free survival (Yiangou et al, 1997); However, bFGF was expressed less in the malignant tissue than the non-malignant breast tissue. In the study of Blanckaert et al (1998) almost all breast tumours contained high-affinity bFGFR, and the patients expressing high levels of bFGFR had a more favourable prognosis. In prostate cancer, Giri et al (1999) found that bFGF is significantly increased relative to the normal prostate tissue and that it is localised in stromal fibroblasts and endothelial cells but not malignant cells. In a subset of prostate cancers, however, these authors observed overexpression of both FGFR-1 and FGFR-2 in the epithelial cells, which correlated with poor differentiation.

Recently, intracellular bFGF has been detected in several lymphoproliferative diseases and was associated with more advanced or refractory disease. In B cells derived from chronic lymphocytic leukaemia, elevated levels of intracellular levels were correlated with disease stage and were associated with resistance to fludarabine (Menzel et al, 1996). Gruber et al (1999) showed that in hairy cell leukaemia, another type of chronic B-cell leukaemia, the leukemic cells express bFGF, which in turn, may mediate the resistance to chemotherapy and survival of the malignant cells. Vacca et al (1999) were the first to demonstrate a significant increase in bone marrow angiogenesis (evaluated as microvessel area) in patients with active multiple myeloma (MM) compared with patients with nonactive $\mathrm{MM}$ and monoclonal gammopathy of undetermined significance (MGUS). Evaluation of bFGF in plasma cell lysates by immunoassay showed significantly higher levels in cells of the patients with active MM compared with nonactive MM and MGUS patients. However, when all the patients were considered, there was no significant correlation between individual plasma cell bFGF levels and bone marrow neovascularisation. It has recently been reported that patients with MM who respond to chemotherapy show a significant decrease in serum bFGF levels, whereas nonresponders do not (Sezer et al, 2001).

In the present study, we did not detect a significant change in serum bFGF levels after 2-3 cycles of chemotherapy, nor did we find a correlation between MVC and NHL histology or grade or between MVC and prognosis. One explanation might be the microvessel counting method used. We did observe a lack of microvessels 
in the follicular areas of follicular lymphoma (Figure 1) but there were many microvessels in the interfollicular areas, and those areas with the greatest number of microvessels ('hot spots') were counted.

Unlike Salven et al (1999), we did not find that pretreatment serum bFGF level is associated with poor overall survival. This difference might be attributable to the relatively small number of patients in our study. Nevertheless, the sample was large enough to yield a highly significant correlation between bFGF expression and poor PFS and overall survival. We also found that the MVC did not correlate with the expression of bFGF, the expression of its receptor, or patient survival. This might suggest that the autocrine or paracrine loop involving the lymphoma cells is more important in NHL than the paracrine loop involving the endothelial cells.

Beside autocrine loop activation, lymphoma cells expressing bFGFRs may respond to bFGFs produced by other cell types or released from the extracellular matrix in a paracrine fashion. We speculate that as the tumour becomes more aggressive, it also becomes independent of stromal paracrine factors by the establish-

\section{REFERENCES}

Basilico C, Moscatelli D (1992) The FGF family of growth factors and oncogenes. Adv Cancer Res 59: 115-165

Bikfalvi A, Klein S, Pintucci G, Rifkin D (1997) Biological roles of fibroblast growth factor-2. Endocrine Rev 18: $26-42$

Birnbaum D, deLapeyriere O, Adnane J, Dionne C, Crumley G, Jaye M, Schlessinger J, Xerril L, Escot C, Gaudray P (1991) Role of FGFs and FGF receptors in human carcinogenesis. Ann N Y Acad Sci 638: 409-411

Blanckaert VD, Hebbar M, Louchez MM, Vilain MO, Schellimg ME, Peyrat JP (1998) Basic fibroblast growth factor receptors and their prognostic value in human breast cancer. Clin Cancer Res 4: 2939-2947

Dellacono F, Spiro J, Eisma R, Kreutzer D (1997) Expression of basic fibroblast growth factor and its receptor by head and neck squamous carcinoma tumor and vascular endothelial cells. Am J Surg 174: 540-544

Folkman J (1990) What is the evidence that tumors are angiogenesis dependent? J Natl Cancer Inst 82: 4-6

Giri D, Ropiquet F, Ittmann M (1999) Alteration in expression of basic fibroblast growth factor (FGF) 2 and its receptor FGFR-1 in human prostate cancer. Clin Cancer Res 5: $1053-1071$

Gruber G, Schwarzmeier JD, Shehata M, Hilgarth M, Berger R (1999) Basic fibroblast growth factor is expressed by CD19/CD11c-positive cells in hairy cell leukemia. Blood 94: 1077 - 1085

Harris NL, Jaffe ES, Diebold J, Flandrin G, Muller-Hermelink HK, Vardiman J, Lister TA, Bloomfield CD (1999) World Health Organization classification of neoplastic diseases of the hematopoietic and lymphoid tissues: Report of the Clinical Advisory Committee Meeting, Airline House, Virginia, November 1997. J Clin Oncol 17: 3835-3849

Iruela-Arispe ML, Dvorak HF (1997) Angiogenesis: A dynamic balance of stimulators and inhibitors. Thromb Haemost 78: 672-677

Mangi MH, Newland AC (2000) Angiogenesis and angiogenic mediators in haematological malignancies. Br J Haematol 111: 43-51

Menzel T, Rahman Z, Calleja E, White K, Wilson EL, Wieder R, Gabrilove J (1996) Elevated intracellular level of basic fibroblast growth factor correlates with stage of chronic lymphocytic leukemia and is associated with resistance to fludarabine. Blood 87: 1056-1063

Ohta T, Yamamoto M, Numata M, Iseki S, Tsukioka Y, Miyashita T, Kayahara M, Nagakawa T, Miyazaki I, Nishikawa K, Yoshitake Y (1995) Expression of basic fibroblast growth factor and its receptor in human pancreatic carcinomas. Br J Cancer 72: 824-831 ment of an autocrine FGF stimulation that can increase its tumorigenicity.

Our results suggest that bFGF within the lymphoma cells plays an important role in the pathogenesis of NHL and can identify patients with poor outcome. The present study is small and heterogeneous. Further larger studies are required examining specific types of lymphoma to determine in what subtypes the effect is most significant. If true, agents that can suppress bFGF synthesis might have a role in the treatment of resistant NHL. Strategies aimed at decreasing the expression of bFGF and its receptor may be of therapeutic benefit in poor-prognosis NHL.

\section{ACKNOWLEDGEMENTS}

We thank Ilana Cohen for the statistical processing. We thank Gloria Ginzach for the helpful language editing. Supported in part by grants from the Israel Cancer Association, and Rabin Medical Center.
Poon RT, Fan ST, Wong J (2001) Clinical implications of circulating angiogenic factors in cancer patients. J Clin Oncol 19: 1207-1225

Ribatti D, Vacca A, Nico B, Fanelli M, Roncali L, Dammacco F (1996) Angiogenesis spectrum in the stroma of B-cell non-Hodgkin's lymphomas. An immunohistochemical and ultrastructural study. Eur J Haematol 56: 4553

Salven P, Teerenhovi L, Joensuu H (1999) A high pretreatment serum basic fibroblast growth factor concentration is an independent predictor of poor prognosis in non-Hodgkin's lymphoma. Blood 94: 3334-3339

Sezer O, Jakob C, Eucker J, Niemoller K, Gatz F, Wernecke KD, Possinger K (2001) Serum levels of the angiogenic cytokines basic fibroblast growth factor (bFGF), vascular endothelial growth factor (VEGF) and hepatocyte growth factor (HGF) in multiple myeloma. Eur J Haematol 66: 83-88

The International Non-Hodgkin's Lymphoma Prognostic Factor Project (1993) A predictive model for aggressive non-Hodgkin's lymphoma. $N$ Engl J Med 329: 987-994

Toi M, Taniguchi T, Yamamoyo Y, Kurisaki T, Suzuki H, Tominaga T (1996) Clinical significance of the determination of angiogenic factors. Eur $J$ Haematol 14: 2513-2519

Vacca A, Ribatti D, Presta M, Minischetti M, Iurlaro M, Ria R, Albini A, Bussolino F, Dammacco F (1999) Bone marrow neovascularization, plasma cell angiogenic potential, and matrix metalloproteinase-2 secretion parallel progression of human multiple myeloma. Blood 93: 3064-3073

Volm M, Koomagi R, Mattern J, Stammler G (1997) Prognostic value of basic fibroblast growth factor and its receptor (FGFR-1) in patients with nonsmall lung carcinomas. Eur J Cancer 33: 691-693

Yamazaki K, Nagao T, Yamaguchi T, Saisho H, Kondo Y (1997) Expression of basic fibroblast growth factor (FGF-2)-associated with tumor proliferation in human pancreatic carcinoma. Virchow Arch 431: 95-101

Yiangou C, Gomm JJ, Coope RC, Law M, Luqmani YA, Shousha S, Coombes RC, Johnston CL (1997) Fibroblast growth factor 2 in breast cancer: occurrence and prognostic significance. Br J Cancer 75: 28-33 